\title{
Electrochemical Water Treatment Technology in Viet Nam: Achievement \& Future Development
}

\author{
Tran Tan Tien ${ }^{1}$, Duong Hieu Linh ${ }^{1}$, Luong Tan Vu' ${ }^{1}$, Pham Thi Thanh Hoa ${ }^{2}$, \\ Nguyen Thi Thanh Phuong, ${ }^{3}$, Tran Le Luu ${ }^{1, *}$ \\ ${ }^{1}$ Department of Mechatronics and Sensor Systems Technology, Vietnamese German University, Binh Duong, Vietnam \\ ${ }^{2}$ Faculty of Biotechnology \& Environment Engineering, HCMC University of Food Industry, HCMC, Vietnam \\ ${ }^{3}$ Institute of Environment \& Natural Resources, Viet Nam National University, HCMC, Viet Nam
}

Email address:

luu.tl@vgu.edu.vn (T. Le Luu)

${ }^{*}$ Corresponding author

\section{To cite this article:}

Tran Tan Tien, Duong Hieu Linh, Luong Tan Vu, Pham Thi Thanh Hoa, Nguyen Thi Thanh Phuong, Tran Le Luu. Electrochemical Water Treatment Technology in Viet Nam: Achievement \& Future Development. Science Journal of Chemistry. Vol. 5, No. 6, 2017, pp. 87-94. doi: $10.11648 /$ j.sjc. 20170506.13

Received: October 26, 2017; Accepted: November 9, 2017; Published: December 1, 2017

\begin{abstract}
Electrochemical technology is a promising technique for water and wastewater treatment in the world. This technology has many advantages as compact model, saving area, highly removal efficient of non-biodegradable compounds, reduction of secondary by-products. There are some different electrochemical techniques such as electroflotation; electrocoagulation using sacrificial electrodes; direct or indirect electrochemical oxidation using Dimensionally Stable Anodes (DSA) and electrodialysis to separate ions in water. In Vietnam, some researches on water and wastewater treatment by electrochemical technology have been studied in the recently year. In this paper, notable results of studies in the application of water and wastewater treatment by electrochemical technology in Vietnam are reviewed in detail. The researching trends of the authors mainly focused on the laboratory scales and the simulated wastewater. Therefore, there are not enough scientific basis to apply for real treatment plants. In the future, electrochemical methods should be used to study the different types of wastewater at the pilot scales, especially difficult handling wastewater and toxics that biological methods cannot handle effectively.
\end{abstract}

Keywords: Water Treatment, Electrocoagulation, Electroflotation, Electrooxidation, Electrodialysis

\section{Introduction}

Nowadays, the industrial development has achieved many significant goals for the economic growth in Viet Nam. In addition, this process discharged waste into the environment in general and water resource in particular. At present, common methods used for treating wastewater are physical, chemical and biological methods. However, these methods have not always achieved satisfactory results with increasingly stringent discharge regulations. The wastewaters containing heavy metals, phenolic compounds, and non-biodegradable pollutants are very difficult to handle and easily retained in the receiving source, which affect human health. On other hand, traditional physical and chemical methods have relatively high process costs, ineffective or can lead to secondary pollution [1]. Therefore, how to eliminate these biodegradable components in wastewater are essential.

Over the last two decades, electrochemical technology has been studied in the field of wastewater treatment in the world. Many studies have been conducted in the laboratory and some good results have been commercialized. Electrochemical treatment has the following advantages: direct or indirect oxidation flexibility; space saving; high-performance processing and can be integrated with environmentally friendly methods [2]. Some types of wastewater have been studied such as: tanning [3, 4], pharmaceuticals [5, 6], toilet wastewater [7], textile [8,9], sugarcane [10, 11], carwash [12], dairy [13] and some other wastewater types.

In Vietnam, over the past ten years, electrochemical techniques in water and wastewater treatment have also been studied. However, this issue is relatively novel and limited in the application. In this article, the current state and evaluation 
of water treatment results in Vietnam by electrochemical will be summarized in detail. Then the suitable future research direction in this field in Viet Nam will be proposed.

\section{Electrochemical Methods for Water Treatment}

\subsection{Electrocoagulation}

Electrocoagulation is technology that is used long-standing and popular today. In this process, when current density is applied, the coagulants are created inside the reactor using sacrificial electrodes, usually iron or aluminum. The metal ions dissolved at the electrode will react to form hydroxide, polyhydroxide compounds that produce a coagulation processing. Chemical reactions in this process can be summarized below [14]:

a. The metal is oxidized into cations at the anode, according to the equation:

$$
\mathrm{M} \rightarrow \mathrm{M}^{\mathrm{Z}^{+}}+\mathrm{Ze}^{-}
$$

b. Water is reduced into hydrogen gas and hydroxide anions at the cathode:

$$
3 \mathrm{H}_{2} \mathrm{O}+3 \mathrm{e}^{-} \rightarrow 3 / 2 \mathrm{H}_{2}+3 \mathrm{OH}^{-}\left(\mathrm{E}^{\mathrm{o}}=0.00 \mathrm{~V} / \mathrm{ENH}\right)
$$

c. General reaction:

$$
\mathrm{M}^{\mathrm{z}^{+}}+\mathrm{zOH}^{-} \rightarrow \mathrm{M}(\mathrm{OH})_{\mathrm{z}}
$$

The advantages and disadvantages of this process are shown in Table 1.

\begin{tabular}{|c|c|}
\hline Advantages & Disadvantages \\
\hline $\begin{array}{l}\text { Ability to treat drinking water and } \\
\text { wastewater }\end{array}$ & $\begin{array}{l}\text { Maintenance required } \\
\text { regularly }\end{array}$ \\
\hline $\begin{array}{l}\text { Combination of oxidation and coagulation } \\
\text { processes }\end{array}$ & $\begin{array}{l}\text { The electrode breaks down } \\
\text { over time }\end{array}$ \\
\hline $\begin{array}{l}\text { Reduced demand for chemicals (replaced by } \\
\text { aluminum and iron electrodes) }\end{array}$ & $\begin{array}{l}\text { Wastewater must has high } \\
\text { conductivity }\end{array}$ \\
\hline \multicolumn{2}{|l|}{ Reduce operating costs } \\
\hline \multicolumn{2}{|l|}{ Reduce the risk of secondary pollutions } \\
\hline \multicolumn{2}{|l|}{ Less generated sludge } \\
\hline \multicolumn{2}{|l|}{ Low energy requirements } \\
\hline Ability to use solar energy & \\
\hline
\end{tabular}

Table 1. Advantages and disadvantages of the electrocoagulation method [14].

\subsection{Electroflotation}

Electrofloatation is a process that pollutants are loaded on the reactor surface by hydrogen and oxygen microbubbles produced by electrolysis of water at the cathode and anode. Generation of the hydrogen and oxygen bubbles are simulated by the equations below:

$$
\begin{aligned}
& \text { At anode: } 2 \mathrm{H}_{2} \mathrm{O}=\mathrm{O}_{2}+4 \mathrm{H}^{+}+4 \mathrm{e} \\
& \text { At cathode: } 2 \mathrm{H}^{+}+2 \mathrm{e}=\mathrm{H}_{2}
\end{aligned}
$$

General reaction: $2 \mathrm{H}_{2} \mathrm{O}=2 \mathrm{H}_{2}+\mathrm{O}_{2}$
Several studies have combined electroflotation and electrocoagulation in a reactor tank. The coagulation processes occur at the anodes generated aluminum hydroxide ions or iron hydroxide ions which combined to the hydrogen and oxygen bubbles are generated at the anodes and cathodes to increase the efficiency of the process. [15].

\subsection{Electrooxidation}

\subsubsection{Direct Oxidation}

In order to reach high performance of direct oxidation process, the anode needs two characteristics: high oxidation potential and corrosion resistance. The oxidation of an organic compound at the anode is simulated in three steps [2]:

a. Discharge of water forming an adsorbed hydroxyl species:

$$
\mathrm{S}\left[\mathrm{H}+\mathrm{H}_{2} \mathrm{O}=\mathrm{S}[\mathrm{OH}]+\mathrm{H}^{+}+\mathrm{e}^{-}\right.
$$

b. The adsorbed $\mathrm{OH}$ is the 'activated state' of water in O-transfer reactions to the organic molecule R:

$$
\mathrm{S}[\mathrm{OH}]+\mathrm{R}=\mathrm{S}[]+\mathrm{RO}+\mathrm{H}^{+}+\mathrm{e}^{-}
$$

c. Co-evolution of $\mathrm{O}_{2}$ by oxidation of water diminishing the current efficiency:

$$
\mathrm{S}[\mathrm{OH}]+\mathrm{H}_{2} \mathrm{O}=\mathrm{S}\left[\mathrm{]}+\mathrm{O}_{2}+3 \mathrm{H}^{+}+3 \mathrm{e}^{-}\right.
$$

\subsubsection{Indirect Oxidation}

Oxidants such as chlorine, hypochlorite, Fenton's reagent, peroxide, peroxodisulphate and ozone are used for indirect oxidation at the anode [14]. The chlorine and hypochlorite are often used because they are easily generated at the anodes. The indirect oxidation mechanisms of the (R) organic compounds are described by the following equations [16]:

$$
\begin{gathered}
\mathrm{Cl}_{2}+\mathrm{H}_{2} \mathrm{O} \rightarrow \mathrm{HOCl}+\mathrm{H}^{+}+\mathrm{Cl}^{-} \\
\mathrm{HOCl} \rightarrow \mathrm{H}^{+}+\mathrm{OCl}^{-} \\
\mathrm{OCl}^{-}+\mathrm{R} \rightarrow \mathrm{CO}_{2}+\text { inorganic ions }+\mathrm{H}^{+}+\mathrm{e}^{-} \\
\mathrm{OCl}^{-}+\mathrm{RCl} \rightarrow \mathrm{R}
\end{gathered}
$$

\subsubsection{Electroreduction}

Similar to electrooxidation method, the electroreduction also has two groups: direct and indirect. The advantages of this direct process are the reducing nitrate at the cathode to generate nitrogen gas and hydroxide ions. However, some undesirable byproducts such as nitrite and ammonia are also produced during the nitrate reduction process. These two byproducts are also involved in the process in which the nitrite is reduced at the cathode, ammonia is oxidized at the anode according to the following equations [16]:

$$
\begin{gathered}
\mathrm{NO}_{3}^{-}+3 \mathrm{H}_{2} \mathrm{O}+5 \mathrm{e}^{-} \rightarrow 1 / 2 \mathrm{~N}_{2}+6 \mathrm{OH}^{-} \\
\mathrm{NO}_{2}^{-}+2 \mathrm{H}_{2} \mathrm{O}+3 \mathrm{e}^{-} \rightarrow 1 / 2 \mathrm{~N}_{2}+4 \mathrm{OH}^{-} \\
2 \mathrm{NH}_{3}+6 \mathrm{OH}^{-} \rightarrow \mathrm{N}_{2}+6 \mathrm{H}_{2} \mathrm{O}+6 \mathrm{e}^{-}
\end{gathered}
$$

The electroreduction is often used for the treatment of 
organic dyes that are insoluble in water and poor contact with the electrode surface. It dissolves some chemical substances such as Anthraquinone, Fe-TEA and Glucose to enhance the solubility of dyes and decomposition by indirect reduction. [12].

\subsection{Electrodialysis}

Electrodialysis (ED) is an electrochemical process. This process involves the movement of ions through selective ion-exchange membranes, which are the results of electrostatic attraction between the ion and the two electrodes. In addition to the desalination function, ED can also remove contaminants in water as soluble ions by electrostatic attraction [17].

The advantage of ED is that the recovery rate of water is higher than the Reverse osmosis (RO) process, leading to lower wastewater treatment costs and increased water using efficiency. In addition, the life of the ion-exchange membrane is relatively high. The ED technology will require less energy than the RO when the salinity is less than $5000 \mathrm{mg} / 1$ [17].

\section{Results of Water Treatment by Electrochemical Methods in Viet Nam}

\subsection{Electroflotation and Electrocoagulation}

\subsubsection{Electroflotation}

The electroflotation technology in Vietnam was investigated for pre-treatment of wastewater before aerobic steps. The wastewater output has a COD removal efficiency as $70-80 \%$, Nitrogen removal efficiency as $50-60 \%$. Although this quality has not reached the standard for direct discharge to receiving sources, it is generally feasible for the thorough treatment process of pollution compounds in the next units. Dinh Quang Du et al. (2015) [18] was investigated electroflotation process for pre-treatment of pesticide production wastewater. In this study, the operating parameters of the electrofloatation model include: $45^{\circ}$ of angle electrode, aluminum electrode with $486 \mathrm{~cm}^{2}$ square, $1 \mathrm{~cm}$ of electrode gap, retention time was 30 minutes and $12 \mathrm{~V}$ electrolytic voltage, $\mathrm{H}_{2} \mathrm{O}_{2}$ concentration was $80 \mathrm{mg} / \mathrm{L}$ and $30 \mathrm{mg} / \mathrm{L} \mathrm{FeCl}_{3}$ concentration. The results showed that SS, COD, $\mathrm{BOD}_{5}, \mathrm{TKN}$, TP removal efficiency were obtained as $83 \%, 76 \%, 57 \%, 53 \%$ and $82 \%$, respectively. After the flotation process, the dissolved oxygen (DO) value in water increases. Compared with the results of using aerobic bioreactor rollers, the pre-treatment of electroflotation is more effective, which satisfies the requirements for the next biological treatment. Similarly, electroflotation process is applied at the pre-treatment stages, Le Hoang Viet et al. (2015) [19] evaluated the technical feasibility of applying this method for wastewater treatment system in catfish processing facilities. The experimental conditions are similar to the research of Dinh Quang Du. Under these experimental conditions, the SS, COD, BOD5, TKN, TP removal efficiencies were obtained as $83.2 \% ; 76.8 \% ; 68.3 \% ; 66.9 \%$ and $71.4 \%$, respectively. The electroflotation process showed that during the reaction, the metal material on the electrode is decomposition at same performances. Therefore, the bigger the electrode size, the higher removal efficiency.

\subsubsection{Electrocoagulation}

Comparison of anthraquinone dye by two methods: electrocoagulation and electro-Fenton processes. The electrolcoagulation uses an aluminum electrode with 0.5 $\mathrm{mA} / \mathrm{dm}^{2}$ current density, anodic area is twice cathode sizes, the stirring speed in the reaction is $1000 \mathrm{rpm}, 0.5 \mathrm{~g} / \mathrm{L} \mathrm{NaCl}$ solution. During electrochemical reaction, aluminum anode dissolves to generate aluminum hydroxide which remove COD from wastewater. The COD removal efficiency decreased when increasing $\mathrm{COD}$ concentration. At the influent COD concentrations were $600 \mathrm{mg} / \mathrm{l}$ and $1040 \mathrm{mg} / \mathrm{l}$ for $97.33 \%$ and $86.92 \%$ performances respectively in 40 minutes. With the ratio of $\mathrm{H}_{2} \mathrm{O}_{2}: \mathrm{FeSO}_{4}=5: 1$ added to the Fenton reaction, the input COD concentrations were $600 \mathrm{mg} / \mathrm{l}$ and $1040 \mathrm{mg} / \mathrm{l}$ for $69.5 \%$ and $40 \%$ performances, respectively. This results illustrate when the dye concentration increase, the Fenton compounds are not sufficiently decomposed causing reduced efficiency. The comparative dyes removal time of two methods are shown in Figure 1, in the same time COD removal efficiency of electrocoagulation was higher than electro-Fenton reached approximately $90 \%$ performances after 25 minutes. The study also tested on the anthraquinone dye, the electro-Fenton processing efficiency is relatively better at $85 \%$ when the input dye concentration is $458 \mathrm{mg} / 1$. The performance would depend on the types of dye and input concentration (Nguyen Thi Huong, 2009 [20]).

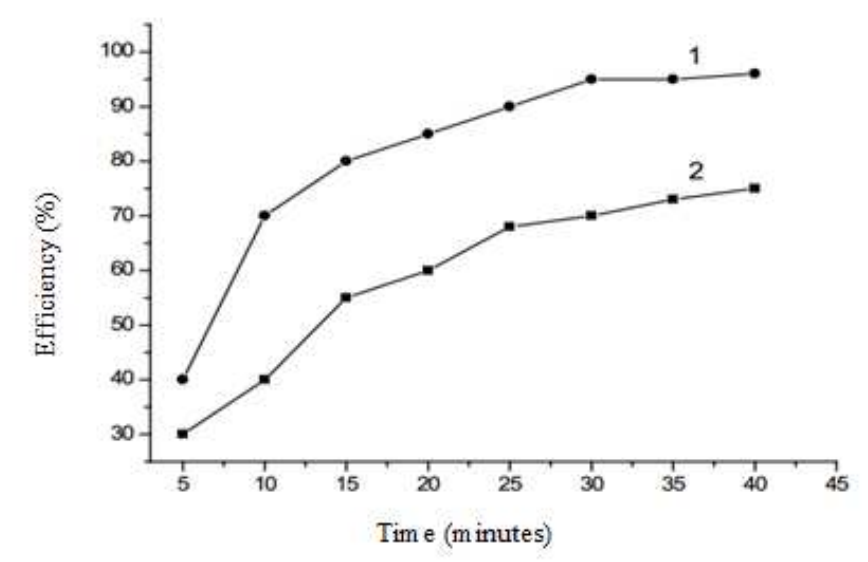

Figure 1. COD removal performance of dyes wastewater (1. Electrocoagulation; 2. Electro-Fenton process [16]).

Evaluating and comparing the performance of electrocoagulation process between AC (alternating current) and DC (direct current). Ho Van Khanh (2004) [21] has investigated to use aluminum electrode to treat dye wastewater with the conditions: $1-1.5 \mathrm{~A} / \mathrm{dm}^{2}$ of current density, a range of $0.5-1 \mathrm{~g} / \mathrm{L} \mathrm{NaCl}$ concentration and dye concentration less than $80 \mathrm{mg} / \mathrm{L}$. The results indicated relatively high removal efficiency, rapid separation rate (2-5 minutes per phase), relatively low dissipation of aluminum 
electrode and less power wastage. With a small dissipation (12\% $-15 \%$ ) while the processing time is quite fast. That demonstrate not only effects of the aluminum colloidal particles but also effects of electric field force between the electrodes. The treatment performance of aluminum electrodes with AC may be similar to DC. However, the DC could remove more types of dyes than the AC.

Electrocoagulation combined between hollow iron electrode and aeration were studied to remove contaminants in plating wastewater. The $\mathrm{Cr}, \mathrm{Ni}, \mathrm{Cu}, \mathrm{Zn}$ removal efficiencies were $99.48 \%, 99.96 \%, 99.91 \%, 99.88 \%$ with input concentrations of $350 \mathrm{ppm}, 105 \mathrm{ppm}, 40 \mathrm{ppm}, 5 \mathrm{ppm}$, respectively. The hollow electrode has treatment performance the same to rectangular electrode. The dissipation of iron electrode was investigated by cyclic voltammetry and Tafel extrapolation methods. The results showed that the dissipation of iron electrode is low but may be apply for the real model with the supports of oxidation of $\mathrm{Fe}^{2+}$ into $\mathrm{Fe}^{3+}$ by oxygen providing. Compared with other technologies for treating of plating wastewater such as RO, ultrafiltration, nanofiltration. The electrochemical provess with hollow electrode has relatively similar efficiency in the range of $99-100 \%$. The optimum conditions for this process are: a 2 liters tank, two hollow iron electrodes with a diameter of each is $7.5 \mathrm{~cm}$ and 6 $\mathrm{cm}, 10 \mathrm{~cm}$ of height, $3 \mathrm{~mm}$ of thickness, and $99 \%$ oxygen gas jetted from the bottom of the tank with flow rates of $4 \mathrm{~L} / \mathrm{min}$, $\mathrm{pH}=5,8.79 \mathrm{~mA} / \mathrm{cm}^{2}$ of current density, electrolytic time of 30 minutes. Power consumptions were $10 \mathrm{kWh} / \mathrm{m}^{3}$ and this method has potential to apply with real wastewater treatment plant (To Thi Hien et al. (2016) [22]).

The electrocoagulation was investigated in combination with micro electrochemical to remove simultaneously $\mathrm{Pb}^{2+}$, $\mathrm{Zn}^{2+}, \mathrm{Cu}^{2+}$ and $\mathrm{F}^{-}$ions in wastewater by Vo An Khue (2014) [23]. The optimum parameters for this method are as follows: initial $\mathrm{pH}$ value $5,5 \mathrm{~V}$ of voltage, removal time is 30 minutes, $60 \mathrm{~g}$ of $\mathrm{Fe}-\mathrm{C}, 20 \sim 27$ mesh of size Fe-C. Under this condition and the initial concentration of ions is $50 \mathrm{mg} / \mathrm{L}, \mathrm{Pb}^{2+}, \mathrm{Zn}^{2+}$, $\mathrm{Cu}^{2+}$ and $\mathrm{F}^{-}$removal efficiency are obtained $99.76 \%, 99.26 \%$, $99.78 \%, 94.03 \%$, respectively. After treatment, the wastewater is very clean and water quality is better than discharge standard, could be discharged directly to the receiving source. The mechanism of fluoride removal is mainly due to the formation of $\mathrm{AlF}_{\mathrm{x}}(\mathrm{OH})_{3 \text {-x }}$ precipitate and a small fraction of the fluoride absorption of iron hydroxide.

Nguyen Ngoc Anh et al. (2010) [24] was carried out the integration of two technologies including USBF (Up-flow Sludge Blanket Filtration) and EC (Electrocoagulation) into once of aquatic wastewater treatment system. A total of eight experiments were conducted, and determined to parameters for design and operation of batch electrochemical tank combined to the USBF with subtracts inside and without subtracts. The results indicated that at $10 \mathrm{~h}$ of total retention time, the USBF performances without subtracts were obtained as: $89.96 \%, 96.33 \%, 97.52 \%, 89.34 \%, 71.95 \%$ for $\mathrm{SS}, \mathrm{COD}$, $\mathrm{BOD}_{5}, \mathrm{TKN}$, TP of parameters, respectively; the USBF performances were combined with subtracts as: $92.63 \%$, $97.16 \%, 98.00 \%, 92.69 \%, 75.85 \%$ for $\mathrm{SS}, \mathrm{COD}, \mathrm{BOD}_{5}, \mathrm{TKN}$,
TP of parameters, respectively. The SS, COD, $\mathrm{BOD}_{5}$, TKN parameters meet QCVN 11: 2008/BTNMT (column A). The optimum conditions of this process are as follows: Anode should be made of aluminum material and cathode should be made of iron material, batch retention time for electrocoagulation tank works at 45 minutes, the distance between the two electrodes is $2 \mathrm{~cm}$, electrode area: $100 \mathrm{~cm}^{2}$, $24 \mathrm{~V}$ of voltages, $1.6 \mathrm{~A}$ of current density.

\subsection{Electrooxidation}

Nguyen Thi Lan Phuong et al. (2016) [25] studied on wastewater containing reactive dye by electrochemical method with 304 stainless steel anode. Under conditions of $\mathrm{pH}$ $=6,30 \mathrm{~mA} / \mathrm{cm}^{2}$ of current density. After only 6 minutes of treatment, this method had COD and color effluents were achieved the QCVN 13: 2008/BTNMT (column B) standard with color influents as a range of 34-8453 Pt-Co and COD $<$ $170 \mathrm{mg} / \mathrm{l}$. The color removal efficiency during this study was relatively high, but the COD removal efficiency was dependent on the original concentration. The input COD concentration of $806 \mathrm{mg} / \mathrm{l}$ was achieved $17 \%$ removal efficiency. However, the input COD concentration less than $806 \mathrm{mg} / \mathrm{l}$ was achieved $70 \%$. With anode and cathode as 304 stainless steel, the oxidation processes occur directly on the electrode surface or indirectly in solution through the $\mathrm{OH}^{*}$ radicals. In addition, the 304 stainless steel electrode also was dissipated during the process to form $\mathrm{Fe}^{2+}$ ions which involved in the electrochemical and electro-Fenton processes increasing the color removal efficiency of draw wastewater. The results of UV-Vis spectroscopy of influent and effluent showed that the azo groups and aromaticity of dye dissolved into simpler compounds, resulting in loss of color and reduced toxicity of the reactive dye.

Research on producing new electrodes on Titanium substract is also being done in Vietnam. Under the manufacturing conditions are a mixture of $0.5 \mathrm{M} \mathrm{SnCl}_{4}+0,5 \%$ $\mathrm{SbCl}_{3}$ in $\mathrm{C}_{2} \mathrm{H}_{5} \mathrm{OH}+\mathrm{HCl}$ solutions with 1:1 of rate and they are heated to $450^{\circ} \mathrm{C}$. Dinh Thi Mai Thanh et al. (2007) [26] have successfully manufactured the working electrode of $\mathrm{SnO}_{2}-\mathrm{Sb}_{2} \mathrm{O}_{5} / \mathrm{Ti}$. Study on the Phenol removal efficiency in wastewater, after 7 hours of electrolysis with $10 \mathrm{~mA} / \mathrm{cm}^{2}$ of current density was obtained low performance at $39 \%, 62.7 \%$ of COD removal efficiency. Compared with some other electrode materials, the treatment efficiencies of this electrode type are not high. Based on this research, Chu Thi Thu Hien (2014) [27] has successfully developed the $\mathrm{Ti} / \mathrm{SnO}_{2}-\mathrm{Sb}_{2} \mathrm{O}_{3} / \mathrm{PbO}_{2}$ inert anodic electrode by combining the decomposition of $\mathrm{SnCl}_{4}, \mathrm{SbCl}_{3}$ solutions at $480^{\circ} \mathrm{C}$ temperature and was covered by $\mathrm{PbO}_{2}$ at 120 minutes. Electrode life is approximately 290 hours. The simulated phenol of $500 \mathrm{mg} / \mathrm{l}$ concentrations showed the highest efficiency of electrochemical treatment as conditions: $\mathrm{pH}=8,50 \mathrm{~mA} / \mathrm{cm}^{2}$ of current density, $7.5 \mathrm{~g} / \mathrm{Na}_{2} \mathrm{SO}_{4}$ concentrations, $1 \% \mathrm{NaCl}$ solution. The phenol removal efficiency was $99.60 \%$ at 360 minutes. The results of electrode application have been manufactured to treat real textile wastewater showed that COD removal efficiency was $95.17 \%$ after 360 minutes with 
constant current intensity of $50 \mathrm{~mA} / \mathrm{cm}^{2}$. The $\mathrm{Cl}^{-}$ions not only a reducing passivity role and activating the electrode but also contributes to the formation of $\mathrm{ClO}^{-}, \mathrm{ClO}_{3}{ }^{-}$and $\mathrm{HO}^{*}$ radicals are phenolic oxidation agents and intermediate products, according to the equations below:

$$
\begin{gathered}
\mathrm{ClO}^{-}(\mathrm{ad})+\mathrm{H}_{2} \mathrm{O}(\mathrm{ad}) \rightarrow \mathrm{Cl}^{-}+2 \mathrm{HO}^{*} \\
\mathrm{ClO}_{3}^{-}(\mathrm{ad})+2 \mathrm{H}_{2} \mathrm{O}(\mathrm{ad}) \rightarrow \mathrm{Cl}^{-}+4 \mathrm{HO}^{*}
\end{gathered}
$$

Similarly, research by Nguyen Ngoc Kien (2013) [28] produced $\mathrm{PbO}_{2}$ anode on carbon graphite subtract combined with 304 stainless steel cathode. The optimum conditions for the synthesis of anode in this study are: $20 \mathrm{ml} / 1$ of $\mathrm{HNO}_{3}$ solution, 0.6 $\mathrm{M}$ of $\mathrm{Pb}\left(\mathrm{NO}_{3}\right)_{2}$ concentration, $0.4 \mathrm{M} \mathrm{Cu}\left(\mathrm{NO}_{3}\right)_{2}, 1 \mathrm{~g} / 1$ of gelatin, $25^{\circ} \mathrm{C}-30^{\circ} \mathrm{C}$ temperature, the current density for electrodialysis is $40 \mathrm{~mA} / \mathrm{cm}^{2}$. The study investigated the phenol removal ability as conditions: $\mathrm{pH}=8,0,7.5 \mathrm{~g} / \mathrm{l}$ of $\mathrm{NaCl}$ solution, $1000 \mathrm{mg} / \mathrm{l}$ of input phenol concentration. The results showed that at the current density of $\mathrm{i}=75 \mathrm{~mA} / \mathrm{cm}^{2}$ which reached $92.7 \%$ removal efficiency at 210 minutes. The results of the X-ray diffraction pattern of the $\mathrm{PbO}_{2}$ electrode show in figure 2 illustrated the line represents the unaltered tetrahedral structure, which indicates that the strength of the electrode is very high.
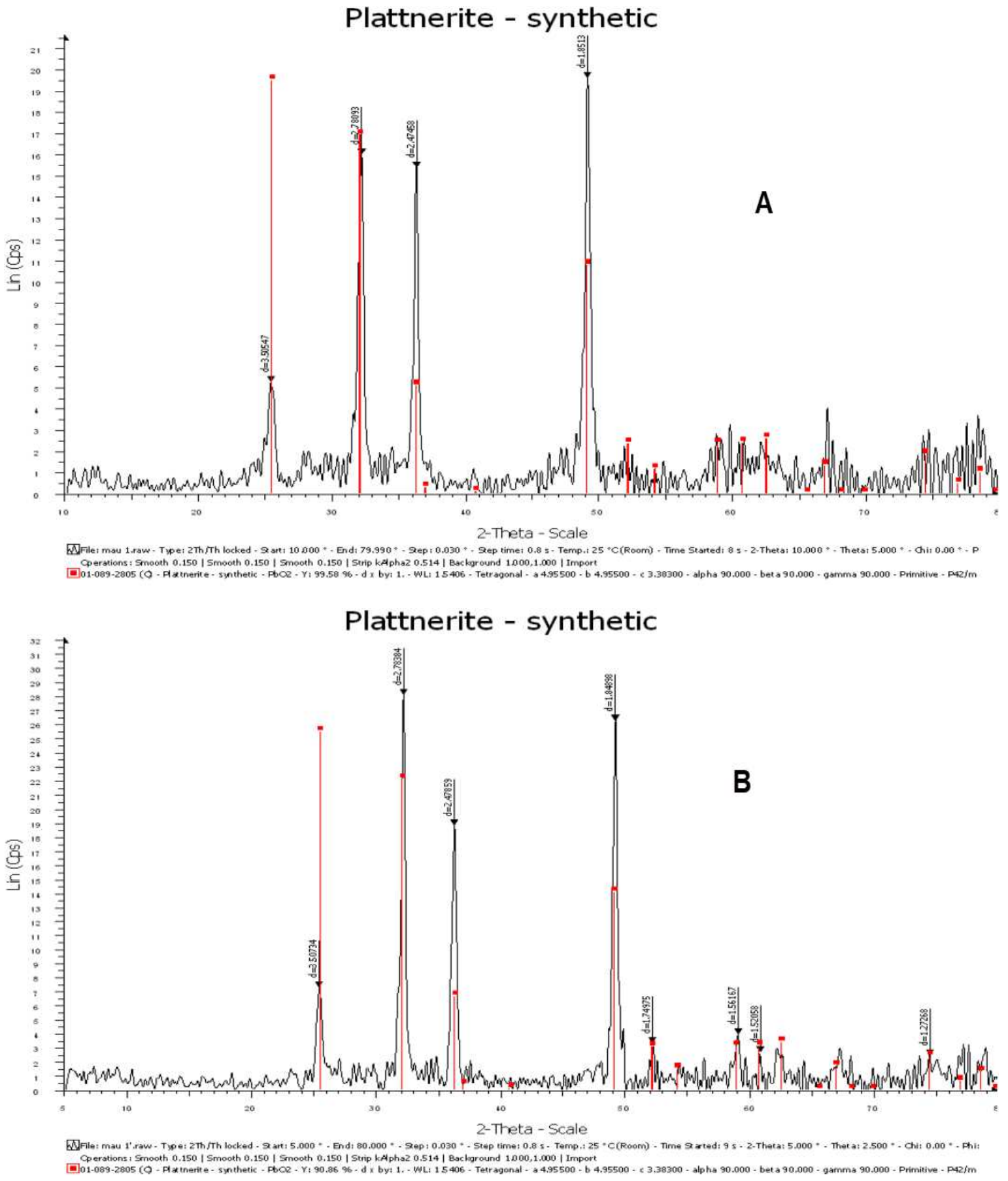

Figure 2. X-ray diffraction pattern of $\mathrm{PbO}_{2}$ sample (A. Before reaction B. After reaction [28]). 
The issue of ammonium removal of wastewater is great interested today. In this field, Pham Cong Minh et al. (2015) [29] has conducted to research on removing of ammonium $\left(\mathrm{NH}_{3}-\mathrm{N}\right)$ for synthetic wastewater by indirect electrochemical oxidation using Platinum anode and stainless steel for cathode. Synthetic wastewater was prepared in a laboratory by dissolving $99 \%$ $\left(\mathrm{NH}_{4}\right)_{2} \mathrm{SO}_{4}$ solution. The surface areas of each electrode are 100 $\mathrm{cm}^{2}$. The model uses circulating pump with 5 liters per minute and stirred at $150 \mathrm{rpm}$. The study conducted to the ammonium removal in direct and indirect electrolyte conditions. The direct electrolysis (input wastewater without chloride addition) of ammonium removal efficiency is very low, approximately $8 \%$ after at 80 minutes. Meanwhile indirect electrolysis (chloride added to wastewater) concentrated that chloride productions are generated at the anode while presence of chloride ions and chlorination of the critical point between chlorine and ammonium to converting to nitrate and $\mathrm{N}_{2}$. Ammonium removal efficiency was above $99 \%$ with indirect electrolysis conditions as: $25 \mathrm{mg} / \mathrm{l}$ of input ammonium concentration, $0.03 \%$ of $\mathrm{NaCl}$ solution, $\mathrm{pH}=7.5,20 \mathrm{~mA} / \mathrm{cm}^{2}$ of current density with removal time at 70 minutes.

Lam Hoa Hung et al. (2017) [30] investigated the p-Nitrophenol ability of degradation by electro-Fenton process using bar graphite electrode. $\mathrm{Pt} / \mathrm{Ti}$ anode type of grid was used and a graphite rod with $9.5 \mathrm{~mm}$ diameter of cathode. This study was carried out considering of reducing $\mathrm{Fe}^{3+}$ to $\mathrm{Fe}^{2+}$ ions and deoxygenation generated to $\mathrm{H}_{2} \mathrm{O}_{2}$ under electrolysis conditions are separated by salt bridges of $1.0 \mathrm{M} \mathrm{Na}_{2} \mathrm{SO}_{4}$ that remove the effects of the anode on the reduction products. Reducing process of $\mathrm{Fe}^{3+}$ to $\mathrm{Fe}^{2+}$ ions conducted in $0.001 \mathrm{M} \mathrm{Fe}_{2}(\mathrm{SO} 4)_{3}$ and $0.05 \mathrm{M} \mathrm{Na}_{2} \mathrm{SO}_{4}$ solutions. The result of the reducing process $\mathrm{Fe}^{3+}$ to $\mathrm{Fe}^{2+}$ on the graphite electrode occurs relatively easily, the reaction was occurred when applied to $1.0 \mathrm{~V}$ voltage and saturated at $3.0 \mathrm{~V}$. However, $\mathrm{Fe}^{3+}$ ions removal efficiency decreased over time as a result of under-voltage condition. When the voltage is constant, the current density supplied to electrodes decrease over time, so the equilibrium voltage at the electrodes surface fall. However, at 75 minutes electrolysis, the $\mathrm{Fe}^{2+}$ ion concentration was accumulated at $2.74 \times 10^{-4} \mathrm{M}$ which are enough to join the electro-Fenton reaction. The $\mathrm{H}_{2} \mathrm{O}_{2}$ is generated more difficult because the activity of graphite electrodes is relatively low. The voltage applied to generate $\mathrm{H}_{2} \mathrm{O}_{2}$ a range of 4.0-7.0 V. The $\mathrm{H}_{2} \mathrm{O}_{2}$ concentration is generated in the range of $9.5 \times 10^{-5}-11 \times 10^{-5} \mathrm{M}$ at 30 to 120 minutes. Upon these conditions may be only enough to handle p-nitrophenol concentration about $5 \mathrm{mg} / \mathrm{l}$. The p-nitrophenol decomposition experiments were performed on a non-membrane electrolyte model with $5 \mathrm{mg} / \mathrm{l}$ input $\mathrm{p}$-nitrophenol concentrations and 0.05 $\mathrm{M} \mathrm{Na}_{2} \mathrm{SO}_{4}$ solution. The results illustrated input voltage of $7 \mathrm{~V}$, $\mathrm{pH}=3$, the p-nitrophenol removal efficiency was greater than $90 \%$ at 120 minutes. However, influent p-nitrophenol concentration of this study was too small because of low active electrode. Therefore, it is necessary to improve the performance of the graphite electrode for appling in real.

Dinh Thi Mai Thanh et al. (2009) [31] used graphite anode to treat the Phong Khe paper wastewater by electro-Fenton method. The anode and cathode electrodes are graphite materials with $8 \mathrm{~cm}^{2}$ surface areas, $15 \mathrm{~mA} / \mathrm{cm}^{2}$ of current density, $\mathrm{pH}=3,1 \mathrm{mM} \mathrm{Fe}^{2+}$. Under those conditions, COD concentration has removed form $1280 \mathrm{mg} / \mathrm{l}$ to $160 \mathrm{mg} / \mathrm{l}$ at 35 minutes. This study showed that when $\mathrm{pH}$ value increases to causing $\mathrm{H}^{+}$ion concentration decrease, the $\mathrm{H}_{2} \mathrm{O}_{2}$ producing reaction is good but $\mathrm{Fe}^{2+}$ ion concentration reducing. Therefore, the $\mathrm{OH}^{*}$ radical is generated that caused to decrease the organic decomposition efficiency. The research has compared the performance between three methods: electrochemical, electro-Fenton and Fenton's reagent technologies on paper industry wastewater. The results showed that high-to-low removal efficiency are electro-Fenton, Fenton's reagent and electrochemical respectively. Electrochemical method was the least performance because the only oxidation agent is electrolysis process but the graphite electrode has low decomposition efficiency. Fenton's reagent method has the disadvantage that generated $\mathrm{Fe}^{2+}$ is low because the $\mathrm{H}_{2} \mathrm{O}_{2}$ concentration decreases over time. The presence of strong oxidizing agents are $\mathrm{OH}^{*}$ and $\mathrm{HO}_{2}{ }^{*}$ radicals so removal efficiency of Fenton electrochemical is higher than other two methods. Nguyen Duc Dat Duc et al. (2016) [32] conducted the same study to use graphite anode to remove color of real textile wastewater by electro-Fenton process. The results showed that optimal conditions of the process were as: $\mathrm{pH}=3.11,1.82 \mathrm{mM} \mathrm{Fe}{ }^{2+}$ (this concentration is higher than the research of Dinh Thi Mai Thanh, 2009), $19 \mathrm{~V}$ of current density. The color removal efficiency reached over $96 \%$ at 30 minutes and color concentrations reduce from $1500 \mathrm{Pt}-\mathrm{Co}$ to $46 \mathrm{Pt}-\mathrm{Co}$. This research was contradictory to the study by Lam Hoa Hung (2017) when the voltages above $7 \mathrm{~V}$ do not increase the p-nitrophenol treatment efficiency.

Azodyes from textile wastewater most commonly have complex carbonaceous structures that are difficult to decompose using traditional methods such as physiological and biological methods. Nguyen Thi Le Hien et al. (2009) [33] carried out removing Red metyl by electro-Fenton method with working anode is graphite covered $\mathrm{Cu}_{1.5} \mathrm{Mn}_{1.5} \mathrm{O}_{4}$ and without covered $\mathrm{Cu}_{1.5} \mathrm{Mn}_{1.5} \mathrm{O}_{4}\left(5 \mathrm{~cm}^{2}\right.$ electrode area). Cathode is platinum grip and Calomel saturated $\mathrm{KCl}$ is reference electrode. In this study, the reaction was concentrated in the cathode with deoxidation process produces $\mathrm{H}_{2} \mathrm{O}_{2}$. Fenton's reagent process is formed from $\mathrm{H}_{2} \mathrm{O}_{2}$ combined to $\mathrm{Fe}^{2+}$ ion which create to $\mathrm{OH}^{*}$ radicals to destroy pollutants. Under optimal conditions as: $-0.6 \mathrm{~V} / \mathrm{SCE}$ cathodic voltage, oxygen flow as $1 \mathrm{~L} / \mathrm{m}, \mathrm{pH}=3,1 \mathrm{mM} \mathrm{Fe} \mathrm{SO}_{4}, 0.1 \mathrm{M} \mathrm{Na}_{2} \mathrm{SO}_{4}$ of electrolyte solution, $0.185 \mathrm{mM}$ of Red - Methyl. Effluent COD concentration is $50 \mathrm{mg} / \mathrm{l}$ after at 24 hours electrolysis when the input COD concentration of $1300 \mathrm{mg} / \mathrm{l}$. Investigation effect of $\mathrm{H}_{2} \mathrm{O}_{2}$ generated by cathode with aeration and no aeration. The results showed that reducing of dissolved oxygen available in water without aeration is not high performance. However, performance unchanged if aeration is greater than the saturation level of reaction at $1 \mathrm{~L} / \mathrm{m}$ flow rate. A mount of $\mathrm{Fe}^{2+}$ added also has a great influence on processing. The amount of 
$\mathrm{Fe}^{2+}$ less than $1 \mathrm{mM}$ concentration is not enough to total creating $\mathrm{H}_{2} \mathrm{O}_{2}$ generated, but if $\mathrm{Fe}^{2+}$ more $1 \mathrm{mM}$ that decreases efficiency. A mount of $\mathrm{Fe}^{2+}$ ion concentration redundancy is oxidized to create $\mathrm{Fe}^{3+}$ ion at anodic electrode, the pair of $\mathrm{Fe}^{2+} / \mathrm{Fe}^{3+}$ oxidation-reduction reaction redundancy will occur consecutive reaction on anodic and cathodic electrodes that decrease electrical efficiency. The results illustrated to $\mathrm{Cu}_{1.5} \mathrm{Mn}_{1.5} \mathrm{O}_{4}\left(\mathrm{C} / \mathrm{Ppy} / \mathrm{Cu}_{1.5} \mathrm{Mn}_{1.5} \mathrm{O}_{4}\right)$ anode has the highest processing efficiency. In the same study, Nguyen Thi Le Hien et al. (2010) [34] repeated the study on Orange-Methyl by $\mathrm{C} / \mathrm{Ppy} / \mathrm{Cu}_{1,5} \mathrm{Mn}_{1,5} \mathrm{O}_{4}$ anode. The results showed that, at 1 $\mathrm{mA} / \mathrm{cm}^{2}$ of current density, $\mathrm{pH}=3$, aeration flow rate of 0.5 $\mathrm{L} / \mathrm{m}, 1 \mathrm{mM} \mathrm{Fe}^{2+}$. Orange-Methyl has lost its color completely after 15 hours treatment. The UV-Vis spectrocopy at the treatment sites showed that peak characterization of the Orange-Methyl was lost. At $229 \mathrm{~nm}$ wavelength there is a new peak which indicates the presence of $\mathrm{OH}^{*}$ radicals involved in the decomposition of the azo color group.

\subsection{Electrodialysis}

Electrodialysis is a relatively high efficiency of desalination technology in parallel with Reverse Osmosis technology (RO). However, there are some disadvantages compared to RO technology, so it is not widely to use. Nguyen Hoai Chau et al. (2005) [35] have applied this technology to remove salinity, hardness and suspended solid in ground water with the experimental model scale of $100 \mathrm{l} / \mathrm{h}$ capacitys. The research has compared the performance of three different membranes: Vietnamese membrane made from cellulose acetate; Russian membranes and US membranes. The cylindrical membrane is $200 \mathrm{~mm}$ of diameter and $12.56 \mathrm{~cm}^{2}$ area of each. The working electrode is made of Titanium covered an anti-corrosive layer. The results showed that three membranes had similar performance that reached as $83 \%, 66 \%, 65 \%$ performance for hardness, suspended solid, desalination removal efficiencies respectively. This study demonstrates that electrolysis technology has potential in field of desalination with low power consumption, not over $1 \mathrm{kWh}$ per $1 \mathrm{~kg}$ salt to be removed. However, this method still has some limitations that affect the performance by osmosis and electro-osmosis process, the fouling membranes by presence of organic and inorganic substances.

In addition to desalination, the electrodialysis is also investigated for the treatment of nitrogen compounds in groundwater. Model of 30-60 1/h capacity included titanium electrodes covered by noble metal oxide layer for anti-corrosive 53 VDC of voltage, a range of $0.75-1.5 \mathrm{~A}$ current density. The results illustrated over $99 \%$ ammonium removal efficiency when input ammonium concentration was $10.4 \mathrm{mg} / \mathrm{l}$. The nitrite and nitrate removal efficiency were $80 \%$ and $60 \%$, respectively. The power consumption for this process ranged from 1.2 to 2.5 $\mathrm{kWh} / \mathrm{m}^{3}$ (Nguyen Thu Tra, 2005 [36]).

\section{Conclusion}

In conclusion, the electrochemical methods in Vietnam to treat water and wastewater have been investigated and applied but quantities and quality also exceeded. Those technologies have also been studied to combine with other methods that achieved the desired treatment performance. However, the researching trends of the authors mainly focused on the laboratory model scales and the simulated raw water. Therefore, overall efficiency of specific indicators have not been evaluated and applied of real wastewaters. However, the results also provided the technical and economic feasibility of this approach. Previous studies focused on electrocoagulation, although this approach is cheap costs but it was generated secondary sludge which is harmful to environment. So research on electrochemical oxidation should be applied in the future, especially the advanced electrodes that the world is using today. In the future, electrochemical methods should be used to study the different types of wastewater at the pilot model scales, especially difficult handling wastewater and toxics that biological methods cannot handle effectively. In addition, it is necessary to find the optimal operating parameters to saving treatment costs as well as to reusing resources for sustainable development. On the other hand, the electrodialysis technology for desalination is applied to treat salty water in the Mekong Delta also interested in situation affected by climate change. That is also mainly research trends to environmental technology faculty of the Vietnamese German University at the present.

\section{Acknowledgements}

This work is supported by the Vietnamese Ministry of Education and Training (MOET) under the grant 6248/QĐ-BGDĐT.

\section{References}

[1] C. Zhang, Y. Jiang, Y. Li, Z Hu, L. Zhou, M. Zhou, "Three-dimensional electrochemical process for wastewater treatment: A general review," Chemical Engineering Journal, vol. 288, pp. 455-467, 2013.

[2] K. Juttner, U. Galla, H. Schmieder, "Electrochemical approaches to environmental problems in the process industry," Electrochimica Acta, vol. 45, pp. 2575-2594, 2000.

[3] C. Costa, C. Botta, E. Espindola, P. Olivi, "Electrochemical treatment of tannery wastewater using DSA ${ }^{\circledR}$ electrodes," Journal of Hazardous Materials, vol. 153, pp. 616-627, 2008.

[4] L. Szpyrkowicz, S. Kaul, R. Neti, S. Satyanarayan, "Influence of anot material on electrochemical oxidation for the treatment of tannery wastewater," Water Research, vol. 39, pp. 1601$1613,2005$.

[5] M. Garc1-Montoya, S. rrez-Granados, A. Alatorre-Ordaz, R. Galindo, R. Ornelas, J. M. Peralta-Hernandez, "Application of electrochemical/BDD process for the treatment wastewater effluents containing pharmaceutical compounds," Journal of Industrial and Engineering Chemistry, vol. 31, pp. 238-243, 2015.

[6] Y. Lan, C. Coetsier, C. Causser, K. G. Serrano, "On the role of salts for the treatment of wastewaters containing pharmaceuticals by electrochemical oxidation using a boron doped diamond anode," Electrochimica Acta, vol. 231, pp. 309-318, 2017. 
[7] X. Huang, Y. Qu, C. Cid, C. Finke, "Electrochemical disinfection of toilet wastewater using wastewater electrolysis cell," Water Research, vol. 92, pp. 164-172, 2016.

[8] F. Orts, A. I. del Río, J. Molina, J. Bonastre, F. Cases, "Electrochemical treatment of real textile wastewater: Trichromy PROCION HEXL", Journal of Electroanalytical Chemistry, doi: 10.1016/j.jelechem.2017.06.051, 2017

[9] J. Zou, X. Peng, M. Li, Y. Xiong, B. Wang, F. Dong, B. Wang, "Electrochemical oxidation of COD from real textile wastewaters: Kinetic study and energy consumption," Chemosphere, vol. 171, pp. 332-338, 2017.

[10] O. P. Sahu, P. K. Chaudhari, "Electrochemical treatment of sugar industry wastewater: COD and color removal," Journal of Electroanalytical Chemistry, vol. 739, pp. 122-129, 2015.

[11] O. Sahu, D. Govardhana, R. RichaGopal, A. Tiwari, D. Pal, "Treatment of wastewater from sugarcane process industry by electrochemical and chemical process: Aluminum (metal and salt)," Journal of Water Process Engineering, vol. 17, pp. 50-62, 2017.

[12] Z. B. Gonder, G. Balcioglu, I. Vergili, Y. Kaya, "Electrochemical treatment of carwash wastewater using $\mathrm{Fe}$ and $\mathrm{Al}$ electrode: Techno-economic analysis and sludge characterization", Journal of Environmental Management, vol 200, pp. 380-390, 2017.

[13] V. Markou, M. C. Kontogianni, Z. Frontistis, A. G. Tekerlekopoulou, A. Katsaounis, D. Vayenas, "Electrochemical treatment of biologically pre-treated dairy wastewater using dimensionally stable anodes," Journal of Environmental Management, vol. 202, pp. 217-224, 2017.

[14] J. Hakizimana, B. Gourich, M. Chafi, Y. Stiriba, C. Vial, P. Drogui, J. Naja, "Electrocoagulation process in water treatment: A review of electrocoagulation modeling approaches," Desalination, vol. 404, pp. 1-21, 2017.

[15] C. Wanga, W. Choub, Y. Kuoa, "Removal of COD from laundry wastewater by electrocoagulation / electroflotation," Journal of Hazardous Materials, vol. 164, pp. 81-86, 2009.

[16] W. T. Mook, M. K. Aroua, G. Issabayeva, "Prospective applications of renewable energy based electrochemical systems in wastewater treatment: A review," Renewable and Sustainable Energy Reviews, vol. 38, pp. 36-46, 2014.

[17] P. V. Hoan, T. T. T Khuong, "An effective desalination technology for domestic water supply for rural population groups in the Mekong Delta," Can Tho University Journal of Science, vol. 45, pp. 33-42, 2016.

[18] D. Q. Du, D. T. H. Nhi, "Study on removal efficiency of plant protection products wastewater by electrocoagulation with Fenton agents combined aerobic biological rotating cage," The graduate thesis, Can Tho University, 2015.

[19] L. H. Viet, D. T. N. Mai, D. T. Phuong, N. V. C Ngan, "Evaluation of electroflotation efficiency of catfish wastewater treatment," Can Tho University Journal of Science, vol. 39, pp. 83-89, 2015.

[20] N. T. Huong, "Textile wastewater treatment efficiency by electrocoagulation and Fenton oxidation methods," Journal of Science and Technology, Da Nang University, vol. 6, pp. 102-106, 2009.

[21] H. V. Khanh, "Study on the application of alternating current (AC) in textile wastewater treatment," Journal of Chemistry, vol. 42, pp. 5-7, 2004.

[22] T. T. Hien, L. M. Hoang, N. T. P Thao, N. S. Phu, "Plating wastewater treatment by electrocoagulation using aeration tank with cylindrical electrodes," Journal of Science and Technology Development, vol. 19, pp. 246-250, 2016.

[23] V. A. Khue, "Study on electrocoagulation combined microelectrolyte for treating heavy metal ions and fluoride in wastewater," Journal of Science and Technology - Da Nang University, vol. 7, pp. 15-18, 2014.

[24] N. N. Anh, N. M. Tung, "Study on aquatic wastewater the treatment by electrochemical method combined to USBF technology," Graduate thesis, Can Tho university, 2010.

[25] N. T. L Phuong, N. N. Lan, T. T. Hien, T. T. A. Ngoc, "Treatment of reactive dye wastewater by electrochemical methods with 304 stainless steel anode," Journal of Chemical, Physical and Biological Analysis, Vol 21, No. 2, pp. 27-35, 2016.

[26] Đ. T. M. Thanh, N. T. L. Hien, "Phenol oxidation on $\mathrm{SnO}_{2}-\mathrm{Sb}_{2} \mathrm{O}_{5} / \mathrm{Ti}$ anode," Journal of Chemistry, vol. 47, pp. 668673, 2007.

[27] Hien T. T. C, "Study on the electrochemical by $\mathrm{Ti} / \mathrm{SnO}_{2}-\mathrm{Sb}_{2} \mathrm{O}_{3} / \mathrm{PbO}_{2}$ anodic electrode in organic compound solutions," Doctoral of Chemistry thesis, Institute of Chemistry - Vietnam Academy of Science and Technology, 2014.

[28] N. N Kien, "Research on improving of manufaturing process on $\mathrm{PbO}_{2}$ anode based on carbon graphite subtract and observation of phenol oxidation on $\mathrm{PbO}_{2}$ anode," Science research topic, Ba Ria Vung Tau University, 2013.

[29] P. C. Minh, N. N. Dung, Y. S. Yoona, “Ammonium $\left(\mathrm{NH}_{3}-\mathrm{N}\right)$ removal in wastewater by indirect electrochemical oxidation using Platin anode," Journal of Military Science and Technology Research, (55 years celebration), 2015.

[30] L. H. Hung, N. T. An, Đ. V. H. Thien, N. Q. Long, "Decomposition of p-nitrophenol by Fenton electrochemical using bar graphite electrodes," Can Tho University Journal of Science, vol. 49, tr. 27-33, 2017

[31] Đ. T. M. Thanh, M. X. Huong, Đ. T. Hai, "Wastewater treatment from paper industry by Fenton electrochemical methods,", Journal of Chemistry, vol. 47, pp. 180-185, 2009.

[32] N. Đ. Đ. Đuc, Đ. H. Yen, N. T. K. Ngan, Đ. M. Trung, “Color removal from textile wastewater by Fenton electrochemical with graphite electrodes," Journal of Thu Dau Mot University, No. 5, pp. 16-24, 2016.

[33] N. T. L. Hien, T. T. Tuoi, "Red-Methyl mineralization by Fenton electrochemical," Journal of Chemistry, vol. 47, pp. 207-212, 2009.

[34] N. T. L Hien, H. T. M. Hanh, "Orange-Methyl mineralization by Fenton electrochemical using Polypyrrol/oxit composit anode," Journal of Science and Technology, vol. 48, pp. $105-112,2010$.

[35] N. H. Chau, C. V. Chung, L. X. Thinh, "Some results of researching salty water by using self-extracting electrodialysis device," Journal of Science and Technology, vol. 43, pp. 114-120, 2005.

[36] N. T. Tra, "Evaluation on treatment efficiency of nitrogen compounds in groundwater by electrodialysis (ED)," Graduate thesis, Hanoi University of Natural Sciences, 2005. 